\title{
EFFECT OF STIRRING SPEED AND FLOW PATTERN ON THE MICROSTRUCTURE OF A RHEOCAST AL-MG ALLOY
}

\author{
P. Melali*, P. Ashtijoo, B. Niroumand \\ Department of Materials Engineering, Isfahan University of Technology, \\ Isfahan 84156-83111, Iran.
}

Received 06.01.2015

Accepted 20.01.2015

\begin{abstract}
The effect of stirring speed and the flow pattern inside a processing crucible were examined in this study. This investigation was performed on the microstructure of mechanically stirred $\mathrm{Al}-8 \% \mathrm{Mg}$. Results reveal that by increasing the stirring speed, morphology of primary particles becomes finer and more spherical. By using baffles, the flow pattern inside the crucible changes. This change causes the melt to accelerate along the crucible wall and producing the finer structure, more spherical and nondendritic. the model, named as nucleation and separation from the wall, posses the ability to explain the microstructure evolution in semi solid fabricated slurry. It must be mentioned that the other model named "fragmentation-agglomeration"' cannot explain the changes in microstructure by using baffles.

Keywords: Semi-solid alloys, Non-dendritic microstructure, Baffle, Stirring speed.
\end{abstract}

\section{Introduction}

Consistent researches have recently focused on semi-solid alloys and many studies have been done on their exclusive rheological and mechanical properties. In the 1970s, the first semi-solid slurry was produced in Massachusetts Institute of Technology (MIT), and since then, various methods of metallic semi-solid grouts have been invented for different applications[1-2]. One of the most common fabrication methods for semi-solid slurry with non-dendritic structure is to create severe tension on the melt during the solidification process through melt mixture [3]. In this method, shear may be generated by means of a mechanical mixer, created by electro-magnetic mixers or even moving the melt through very cursive directions. Mechanical stirring created by such methods affects the mixture in the solid-melt phase region. Dendrites created in the melt during solidification will be fragmented as a result of the shear rate influence, and, finally, a spherical shaped structure will be seen in the solidified fraction instead of dendritic structure. This structure alteration from dendritic to spherical as well as the spherical structure evolution depends on various parameters, most important of which

* Corresponding author: P. Melali, pejman.melali@gmail.com 
include the range and the application procedure of the cutting tension to the solidifying melt [3-6]. Different mechanisms have been provided for the evolution of dendritic structure into spherical structure, most of them which are based on plastic deformation of dendrite arms and their separation from the main arm of dendrite. One of the suggested mechanisms in this respect is the "agglomeration-fragmentation" mechanism in which initial non-dendritic particles are created by fragmentation of dendrite arms into small pieces at the initial solidification stages [7-8]. Therefore, depending on the shear rate, the above particles will agglomerate or sinter and form large clusters with complicated morphology (particle agglomeration). These agglomerates, as a result of applying the high shear rate, are broken into parts (de-agglomerate) and the separated particles will be recreated. According to the above theory, shear rate applied to the whole melt determines the structure dimensions and the amount of initial solid particle agglomeration. In another proposed mechanism, that is "nucleation and separation from the wall”, non-dendritic structure is mostly affected by nucleation on the crucible wall and velocity of melt near the crucible wall. At first, the initial particles are nucleated on the crucible wall and then deformation process and compression of dendrite arms under tension imposed from the melt occurs, while the particles are still stuck to the crucible walls. Within a short time, dendrite morphology will become complicated nondendritic. Finally, as the above particles grow up to a critical limit, they will separate from the wall and scatter into the melt by means of the shear stress imposed to the melt $[8,9,12,13]$. Taking into account the relatively low speed of those particles moving along with the melt, structural changes as a result of applying tension will not be remarkable anymore. Therefore, mechanism of shear rate change is not the only influential factor on semi-solid structure formation $[9,10]$. Other factors including melt fluidity model and velocity of the melt near the crucible wall are very important as well. Recently, other methods such as semi-solid rheocasting (SSR), new rheocasting (NRC) process, and swirled enthalpy equilibration device (SEED) have been suggested rarely based on the application of severe tension on the solidifying melt. In these methods, structural changes as a result of severe nucleation in the melt happen at the initial stages of solidification. Application of semi-solid grout for the fabrication of metallic parts has remarkable advantages, allowing these alloys to be replaced with traditional methods to manufacture some sensitive parts.

This paper investigates the effect of stirring speed and flow pattern inside the processing crucible on the solidification microstructure of a rheocast Al-8\%Mg alloy.

\section{Materials and Methods}

After fabrication of the Al-8\%Mg alloy, for which the composition is shown in Table 1, the alloy cooling curve occurred first and a liquidous temperature around $648^{\circ} \mathrm{C}$ was observed for this alloy. Figure 1 depicts the schematic image of the rheocaster device utilized for the tests. This machine consists of a resistance furnace and a stirrer with height adjustment capability. The crucible used in this study was made of graphite, designed as bottom discharge. Semi-solid slurry was cast directly from the crucible into the steel mould located under the furnace (Figure 1). In each test, $400 \mathrm{~g}$ of melt alloy was heated up to $665^{\circ} \mathrm{C}$. Then, the cylindrical graphite stirrer with a diameter of $3 \mathrm{~cm}$ and the height of $6 \mathrm{~cm}$ was put into the melt, and the mixing process started at $660^{\circ} \mathrm{C}$ with a speed of $500-1000 \mathrm{rpm}$. The melt was cooled to $600^{\circ} \mathrm{C}$, and the solid 
fraction of $30 \%$ was obtained for this alloy according to the Scheil equation (1). After that, the semi-solid alloy was stirred continuously and casted inside the steel mould. Fraction of initial solid, $\mathrm{f}_{\mathrm{s}}$, can be calculated from equation (1):

$$
\mathrm{f}_{\mathrm{s}}=1-\left(\frac{\mathrm{T}_{\mathrm{m}}-\mathrm{T}}{\mathrm{T}_{\mathrm{m}}-\mathrm{T}_{1}}\right)^{\frac{-1}{1-\mathrm{k}}}
$$

where:

$\mathrm{T}_{\mathrm{m}}=$ alloy melting temperature

$\mathrm{T}_{1}=$ Liquidus temperature

$\mathrm{k}=$ elements balance distribution factor

Table 1 Chemical composition of alloy.

\begin{tabular}{cccc}
\hline $\mathrm{Al}$ & $\mathrm{Cu}$ & $\mathrm{Si}$ & $\mathrm{Mg}$ \\
\hline Bal. & 0.0733 & 1.67 & 8.03 \\
\hline
\end{tabular}

In the other two tests, a steel baffle is designed for the crucible and a $\mathrm{TiO}_{2}$ coating is applied to prevent any corrosion and any kind of porosity in melt. Then, earlier tests were repeated by means of baffle. In order to make a comparison, the melt was also solidified from $660^{\circ} \mathrm{C}$ to the room temperature without using the mixer. Table 2 provides the relevant conditions and corresponding microstructures.

Table 2 Test conditions and samples microstructures.

\begin{tabular}{|c|c|c|c|c|c|c|}
\hline \multirow[b]{2}{*}{$\begin{array}{l}\text { Sample } \\
\text { number }\end{array}$} & \multicolumn{3}{|c|}{ Microstructure } & \multirow{2}{*}{$\begin{array}{c}\text { Stirring } \\
\text { speed } \\
\text { (RPM) }\end{array}$} & \multirow{2}{*}{$\begin{array}{l}\text { Fraction } \\
\text { of } \\
\text { solid(\%) }\end{array}$} & \multirow[b]{2}{*}{ Baffle } \\
\hline & Spherical & Roset & Dendritic & & & \\
\hline 1 & - & - & $\checkmark$ & 0 & - & - \\
\hline 2 & - & $\checkmark$ & $\checkmark$ & 500 & 30 & - \\
\hline 3 & $\checkmark$ & $\checkmark$ & $\checkmark$ & 1000 & 30 & - \\
\hline 4 & - & $\checkmark$ & - & 500 & 30 & $\checkmark$ \\
\hline 5 & $\checkmark$ & $\checkmark$ & - & 1000 & 30 & $\checkmark$ \\
\hline
\end{tabular}

Metallographic specimens were polished through standard routines and an optical microscope equipped with an image analyzer was used to study the morphological modification. A $1 \%$ hydrofluoric acid (HF) water solution was used as the etchant for polished samples. The shape factor, compactness, and the equivalent diameter of grains were measured by the image analyzer.

The shape factor, which indicates the spherical shape of the particles, is measured via the equation 2. In this equation $\mathrm{P}$ is the equivalent perimeter of each particle and $\mathrm{A}$ is the equivalent area of each particle. 


$$
\frac{4 \pi A}{P^{2}}=\text { Shape Factor }
$$

In ideal conditions as the particle is completely spherical, the above factor will be equal to 1 while it will be less than 1 in the case of deviation.

Compactness of the structure particles, C, specifying the ratio of particle diameter to the particle length is defined by the equation (3).

$$
\text { Compactness }=\frac{2}{M} \sqrt{\frac{A}{\pi}}
$$

In equation (3) $\mathrm{M}$ is the length of the longest line to be drawn inside the particle and $\mathrm{A}$ is the particle area. Also, if compactness is equal to 1 it indicates ideal conditions (i.e. complete spherical shape). Equivalent diameter of spherical particles was measured by the linear intercept method.

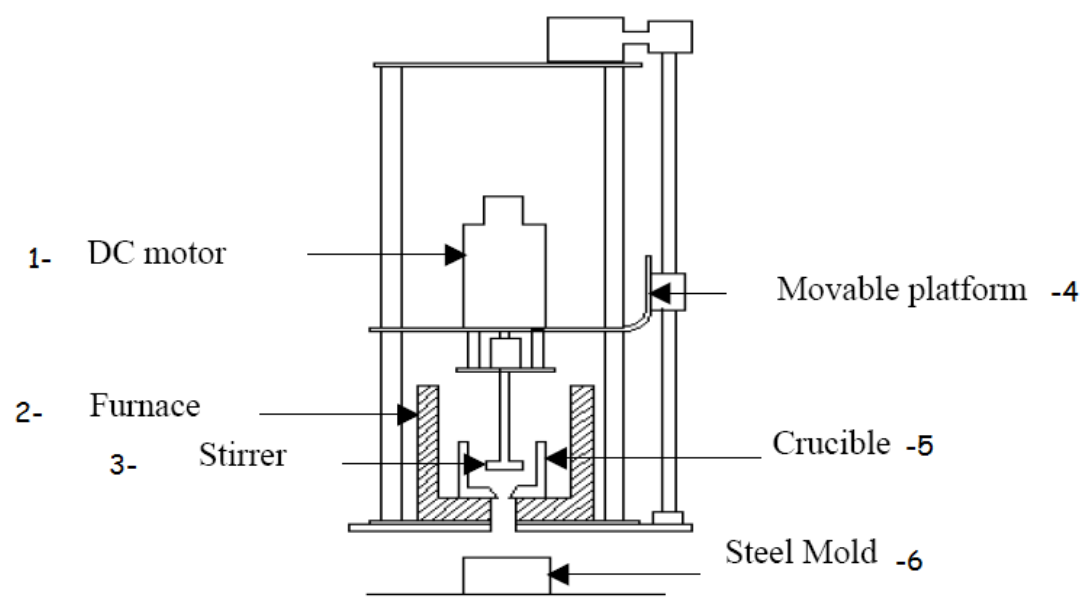

Fig. 1. Schematic drawing of the utilized rheocaster device.

\section{Results and Discussion}

Influence of the mixer speed on the substructure

Figure 2 shows the microstructure of the cast sample which was cooled at room temperature without stirring. According to this figure, coarse dendrites are observed throughout the sample. In addition, coarse grains beside the fine dendritic particles make a non-uniform structure in this sample. Average size of the secondary dendritic arm spacing is measured to be approximately $101 \mu \mathrm{m}$. 


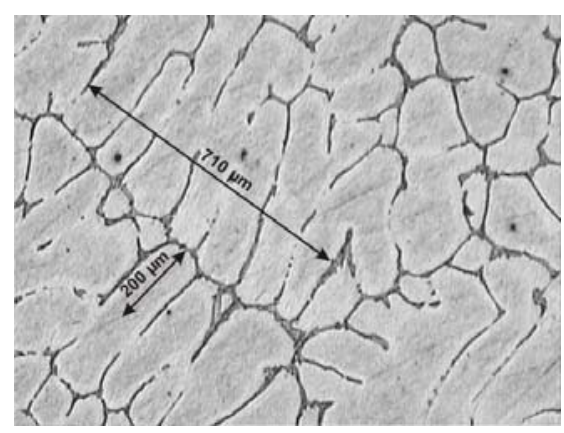

Fig. 2. Microscopic image of a cooled sample in crucible without the mixer.

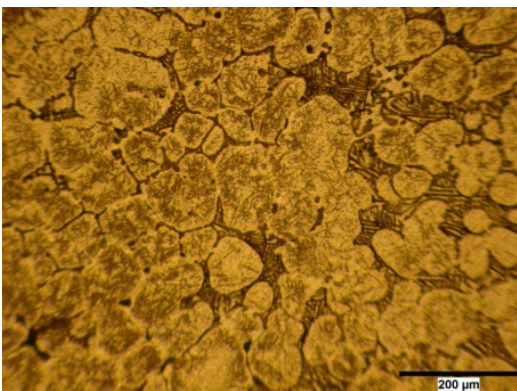

$a$

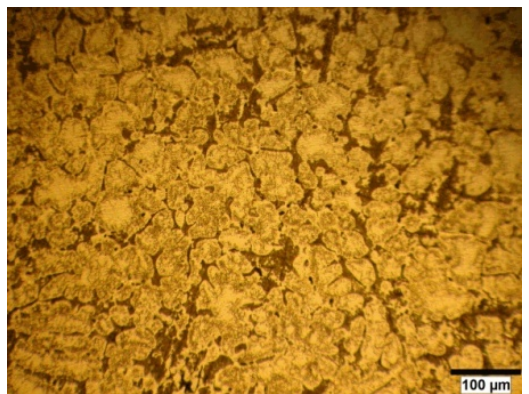

$b$

Fig. 3 Microstructure of a stirred sample; (a) 500rpm, (b) 1000rpm.

Figure (3a) shows the microstructure of a sample which was stirred at $500 \mathrm{rpm}$. Microscopic measurements indicated that the average diameter of the particles in this sample has dramatically decreased. Likewise, there are three types of structural morphology in the structure namely dendritic particles, rosette-shaped, and spherical. When the stirring speed increases to $1000 \mathrm{rpm}$ (Figure 3b), although the influence of the initial dendrites still exists, particle compression of this sample is somewhat higher than in the previous case, and the average diameter of the initial particles has been reduced. In this sample, all rosette-shaped particles present in the first sample became spherical, whereas sharp-edged and convex sides disappeared. Therefore, the roundness factor of the particles was increased by some extent.

\section{The Effect of Using Baffle on Sub-Structure}

In a sample being stirred at $500 \mathrm{rpm}$ along with baffle (Figure 4a), not only has the structure become finer than the similar case without baffle (sample 2), but also diameter of the initial particles is even less than when the stirring speed was 1000rpm (sample 3). In addition, there is no further effect of dendrite or long particles that was previously observed in the other two samples. For this reason, both roundness and compactness modes of the solid particles have increased in relation to the mode without using a baffle. This fact is seen in Figure 5. 


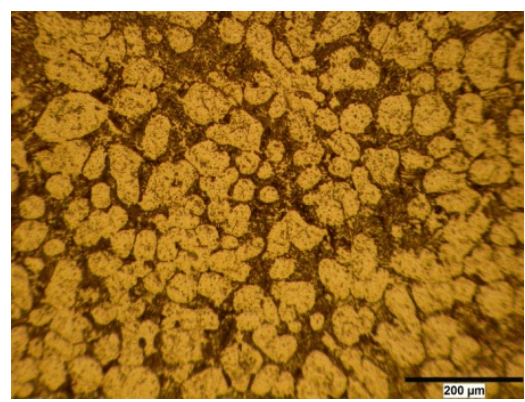

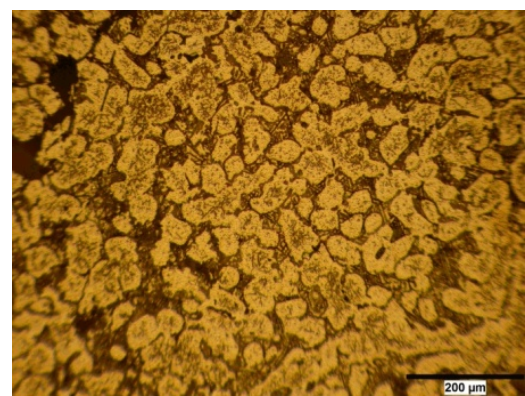

$b$

Fig. 4. Microstructure of samples mixed with a baffle; (a) 500rpm; (b) 1000rpm.

As the stirring speed increases to 1000 rpm along with using a baffle, the particles will become finer and their compactness will increase (Figure 4b). However, small amounts of gas flow or bubbles are observed in the sample microstructure due to the turbulence present in the melt. In this sample, dendritic structure does not exist, and the structure is mostly consisting of rosette-shaped or spherical particles. It is still unknown why the particles shapes have not changed in spite of increase in their compression. However, particles shape factor is more than the gained value for the samples mixed without using a baffle.

Figure 5 a, b and Figure 6 display the influence of stirring speed and the use of a baffle on compactness, roundness, and equivalent diameter of the solid, respectively, of particles for the tests 2 to 5 . According to these figures, as the stirring speed with a baffle in crucibles increases, particle diameter will decrease and roundness and compression parameters will increase. Additionally, it seems that the influence of using a baffle is more significant than the mixing speed, which is very important from the point of view of equipment and the amount of consumed energy.

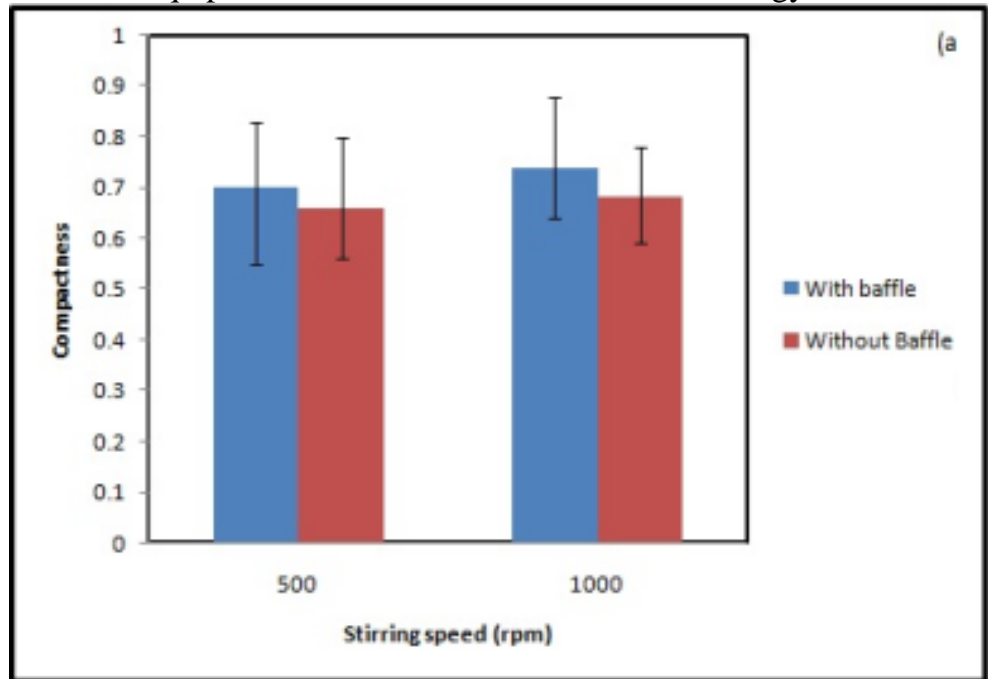




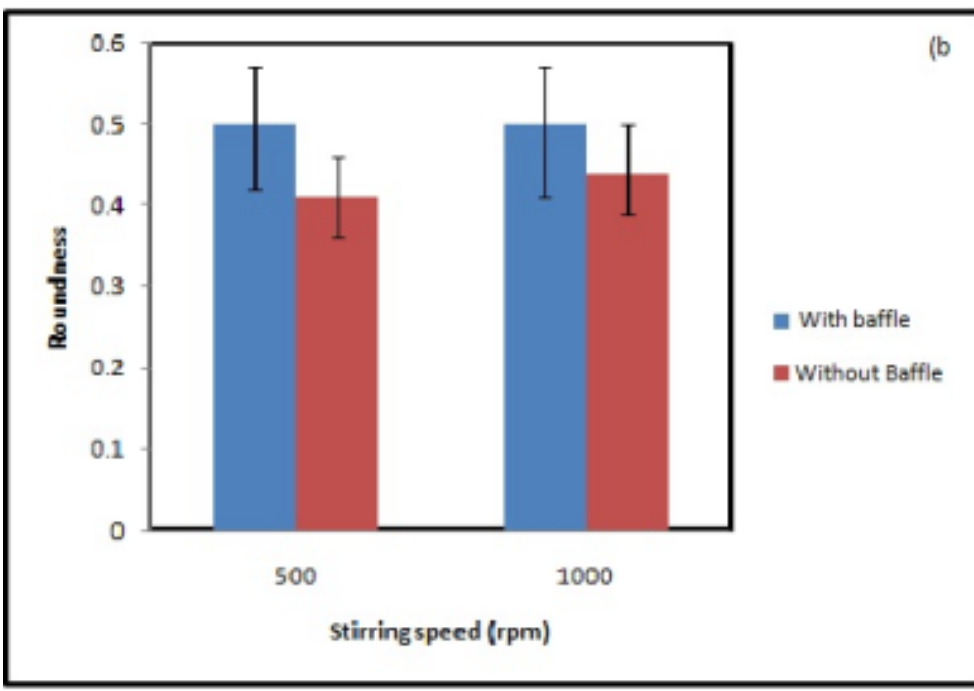

Fig. 5 Effects of stirring speed and use of baffles on (a) Compactness and (b) Roundness.

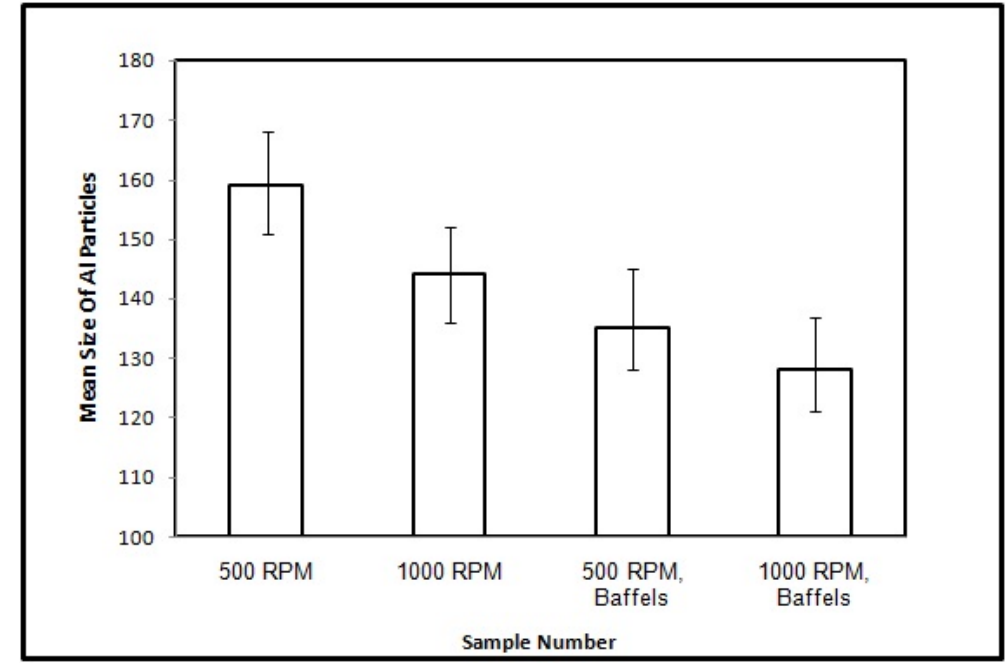

Fig. 6 Equivalent diameter of initial solid particles for different samples.

Justification of structural alterations as the result of an increase in the mixing speed based on the proposed mechanism of agglomeration - fragmentation is feasible. According to these theories, as the shear rate increases in a semi-solid grout, initial dendrites will be more fragmented and gaining little agglomeration opportunity. Consequently, the structure will become finer and the particles will tend to become more spherical due to the higher surface curvature. Higher speed of the melt will assist in this respect. 
However, based upon agglomeration-fragmentation mechanism it is not easily possible to justify structural changes as the result of using a baffle. Investigations[ reveal that adding a baffle to a crucible at a fixed mixing speed has no influence on shear stress created in the melt, but the main role of baffle is to make a layer with a high speed in front of the crucible walls. Therefore, this cannot be a factor for structural alterations of shear stress throughout the melt $[11,14]$.

In contrast, it is possible to justify structural changes as the result of stirring speed increase and the use of a baffle simply by the "nucleation and separation from the wall" mechanism $[10,12,13]$. According to this mechanism, using baffle will increase the melt velocity in front of the crucible wall, and consequently thickness of the borderline layer in contact with the crucible wall will decrease [7-12]. As the result, melt fluidity in front of the crucible wall will be able to separate nuclei from the wall and transport them to the crucible central part within a shorter period of time. As the initial particles are separated from the crucible wall, new particles will be able to nucleate and grow on the wall. Therefore, nucleation rate will increase and the structure will become finer. On the other hand, as the boundary layer thickness in contact with the crucible walls decreases, growing particles will immediately change their forms into the cluster shaped. Therefore, they gain less directed growth opportunity perpendicular to the crucible surfaces, and they will have higher shape and compactness factors. This mode inside the melt is retained due to the existing negative temperature gradient conditions, therefore particle growth will continue uniformly in all directions. The influence of increase in the mixing speed can also be discussed in a similar way.

\section{Conclusion}

1. Applying a shear stress to the solidifying melt of $\mathrm{Al}-8 \% \mathrm{Mg}$ alloy, the modification of dendrite structure morphology will start. As the mixing speed increases to 1000 rpm and a baffle is added to the crucible, the structure of initial solid particles will gradually become rosette-shaped and finally a completely non-dendritic spherical structure will be obtained.

2. Upon increase in the applied shear stress and the use of baffle, the size of initial solid particles decreases, but their roundness and compression will increase.

3. The influence of using a baffle for the modification of the semi-solid alloy structure is more significant than the influence of the mixing speed on the semi-solid slurry.

4. Although justification of these structural alterations is feasible through "nucleation and separation from the walls", agglomeration-fragmentation mechanism is not able to justify the effects of using a baffle on the structure.

\section{References}

[1] D.B. Spencer, R. Mehrabian, M.C. Flemings, J Metallurgical Transactions. (1972), 1925-1932.

[2] M.C. Flemings, J Metallurgical Transactions.22 (1991), 957-981.

[3] R.D. Doherty, H.I. Lee, E.A. Feest, J Materials Scie and Eng. 65 (1984), 181-189.

[4] A. Hellawell, Int Conf Proc of $4^{\text {th }}$ Semisolid alloys and composites, Sheffield (1996), 60.

[5] A. Das, Z. Fan, Int Conf Proc of $7^{\text {th }}$ Semi-Solid Alloys and Composites, Tsukuba (2002), 449. 
[6] D.H. Kirkwood, M. Suery, P. Kapranos, H. Atkinson, K.P. Young, Semi-solid Processing of Alloys. $1^{\text {st }}$ ed, Verlag Berlin Heidelberg: Springer, (2010).

[7] B. Niroumand, K. Xia, Proceedings of the 8th International Conference on SemiSolid Processing of Alloys and Composites, Cyprus, (2004), 06-2.

[8] B. Niroumand, Ph.D thesis, The university of Melbourne, (1997).

[9] P. Falak, B. Niroumand, A. Najafizadeh, Evaluation of a New Mechanism. Proceedings of the 8th International Conference on Semi-Solid Processing of Alloys and Composites, Cyprus, (2004), 11-1.

[10]B. Niroumand, P. Falak, J Scripta Materia. 53 (2005), 53-57.

[11]B. Niroumand, K. Xia, J Materials Scie and Eng. 283 (2000), 70-75.

[12]H. Mirzadeh, B. Niroumand, J Alloys \& Compd. 474 (2009), 257-263.

[13] M. Reisi ,B. Niroumand, J Alloys and Comp. 470 (2009), 413-419.

[14]A. Desouza, R. Pike, The Canadian Journal of Chem Eng. 50 (1972), 15-23. 